Published online: 8 March 2017

(C) The Association of Bone and Joint Surgeons (B) 2017

\title{
CORR $\mathbb{R}$ \\ International-Asia-Pacific
}

\section{CORR $^{\mathbb{R}}$ International-Asia-Pacific: 100 Patients a Day: Teaching Our Rising Stars How to Be Both Busy and Excellent}

\author{
Tae Kyun Kim MD, PhD
}

\section{Introduction}

decided to become an orthopaedic surgeon during my junior year of medical school. Orthopaedics seemed entirely different from other specialties. The surgeons, with their saws, chisels, and hammers, looked like carpenters and the surgical pro-

\section{A Note from the Editor-in-Chief:}

I am pleased to introduce the next installment of "CORR International - Asia-Pacific." In this quarterly column, Professor T. K. Kim covers the issues of moment to orthopaedic surgeons and scientists practicing in the AsiaPacific region, where nearly a quarter of CORR's readers are located. Prof. Kim, from Seoul, South Korea, is an internationally renowned knee surgeon and our Deputy Editor.

The author certifies that neither he, nor any members of his immediate family, have any commercial associations (such as consultancies, stock ownership, equity interest, patent/licensing arrangements, etc.) that might pose a conflict of interest in connection with the submitted article. All ICMJE Conflict of Interest Forms for authors and Clinical Orthopaedics and Related Research ${ }^{\mathbb{R}}$ editors and board members are on file with the publication and can be viewed on request. cedures looked like a mechanics class. The language was unique, seemingly designed for mechanical engineering. I was drawn to the independent nature of orthopaedic surgery; patient care could be conducted without much reliance on other specialties. The uniqueness of orthopaedic surgery-with its broad scope of practice-required visual demonstration and hands-on workshop courses. I just fell in love with the idea of treating patients in this unique way.

But in the Asia-Pacific region, particularly China, India, and Korea, orthopaedic surgeons typically treat more patients in clinic than physicians in other surgical specialties [5, 9]. For example, in a typical half-day clinic, I

The opinions expressed are those of the writers, and do not reflect the opinion or policy of $C O R R^{\circledR}$ or The Association of Bone and Joint Surgeons ${ }^{\circledR}$.

\section{T. K. Kim MD, PhD ( $ه)$}

Department of Orthopaedic Surgery, Seoul National University Bundang Hospital, 82 Gumi-ro 173 beon-gil, Bundang-gu, Seongnam, Republic of Korea

e-mail: osktk2000@yahoo.com; osktk@snubh.org routinely see more than 100 patients. Learning how to handle a patient load of this magnitude with safety, accuracy, and efficiency is not something that is taught-or can be learned-in the classroom.

\section{Algorithmic Approach in Clinic}

In an extremely busy clinic, making the correct diagnosis in such a short period of time is challenging. An algorithmic approach that reflects the prevalent diseases relevant to the particular clinic or region is an efficient way to facilitate the care process, allowing the clinic's staff to spend more time on patient care and administrative work.

In my practice, where I generally see patients with knee issues, I have established a three-step algorithmic approach that works for my office: (1) Identify why the patient is visiting the clinic. Is this a first visit or a return? (2) Review medical records. Collect history, physical findings, imaging studies, and laboratory tests. (3) Decide what to do for the 


\section{CORRß International-Asia-Pacific}

patient-further evaluate, assure and discharge, or make a diagnosis (Fig. 1).

In order to make a diagnosis, the surgeon needs to be aware of any conditions or diseases prevalent to their region. Disease or symptom patterns vary within each region. For example, the presence of varus deformity, which is much more frequent in the Asia-Pacific region than in other regions [8, 10, 11], is an important factor to consider when identifying the underlying causes for symptoms or conditions [2], or predicting disease progression and making treatment plans [7, 15].

By using the algorithmic approach, we can quickly determine how to manage the patient on that day, allowing for more discussion time on treatment options and addressing any patient concerns.

\section{Lean on Mentors}

With such a high volume of patients, inevitably a physician will come across a patient who is dissatisfied with

Step 1: Identify Why Patient Is Visiting

- Conduct patient interview

- Compare first vs. return visit

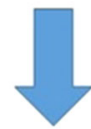

Step 2: Collect Information

- History, physical findings

- Images

- Laboratory tests

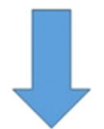

Step 3: Make a Decision

- Evaluate further

- Assure and discharge, or

- Make a diagnosis

Fig. 1 An algorithmic approach can facilitate patient care in an outpatient clinic.

their results, and may elect to pursue a legal path. In my previous column [6], I discussed how a warm and compassionate approach to treating patients could remedy or resolve disputes between patients and physicians before they reach the courts. Still, disputes with patients-resolved or not-can increase the physician's stress level. Many studies suggest that "burnout" is common among orthopaedic surgeons around the world [1, 13, 14] and Asian surgeons are no less vulnerable to stress. Mindfulness-based practice and emotional support from a colleague or mentor can help surgeons cope with the high-stress working environment $[3,12]$ or legal obligations.

Young surgeons are a byproduct of those who came before them. Mentors have the experience to show young surgeons how to maintain a work-life balance, how to treat patients in a busy clinic, and how to always stay focused on the mission-helping patients get better.

Broadly speaking, there is a large difference in the mentorship patterns between the Asia-Pacific region and the West. While teaching in the Western world is more target-specific and professional, the mentor-protégé relationship in the Asia-Pacific region involves a greater personal touch. Although there is a certain hierarchy in the Asian work culture, which to some extent, limits the natural flow of 


\section{CORR® International-Asia-Pacific}

knowledge and information between the two, the mentors are revered by their students in Asian countries and are looked upon with greater respect and privilege. A mentor should be a strong pillar of support in every adverse situation, including professional or personal stresses or dealing with patient issues at outpatient clinics.

\section{Running a Business}

Seeing 100 patients in a given day is more than enough work for an orthopaedic surgeon. However, the day rarely ends when the last patient leaves the clinic. It is quite common in AsianPacific regions for the orthopaedic surgeon to be in charge of the business side of the clinic as well. Healthcare systems vary substantially among countries in Asia, a fact that has important implications to the surgeon in charge of a clinic or hospital. The surgeon must be knowledgeable and updated of pertinent business-related issues, particularly reimbursement systems. Surgeons who act as the practice's de facto chief executive officer should have or be given a proper education on business management and human resources. They should consider attending formal educational courses or seeking in depth advice from senior physicians who are experienced in these matters.
In many instances, our family's healthcare is in the hands of today's young surgeons. How young physicians cope with this massive responsibility will depend on whether they are prepared for the patient load, have a mentor they can count on, and have a diversified education. If young surgeons can obtain all of those characteristics, they will find their job rewarding and meaningful-no matter the patient load.

That is how you stay in love with orthopaedic surgery.

I would like to conclude by quoting a spiritual and inspiring poem by Korean Buddhist monk, Cheong Heo.

When walking across a snow-covered field,

May you stay mindful and wary of chaos.

For the footsteps you take today,

Shall serve as a milestone for others tomorrow [4].

\section{References}

1. Arora M, Diwan AD, Harris IA. Burnout in orthopaedic surgeons: A review. ANZ J Surg. 2013;83:512-515.

2. Chang CB, Koh IJ, Seo ES, Kang YG, Seong SC, Kim TK. The radiographic predictors of symptom severity in advanced knee osteoarthritis with varus deformity. Knee. 2011;18:456460.
3. Goodman MJ, Schorling JB. A mindfulness course decreases burnout and improves well-being among healthcare providers. Int J Psychiatry Med. 2012;43:119-128.

4. Jeong B. The Mirror of Zen: The Classic Guide to Buddhist Practice by Zen Master So Sahn. Boston, MA; Shambhala Publishers: 2003.

5. Jha A. Safdarjung hospital: Volume and efficiency but little time for quality. Available at: https://blogs. sph.harvard.edu/ashish-jha/2012/10/ 04/safdarjung-hospital-volume-andefficiency-but-little-time-for-quality/. Accessed October 13, 2016.

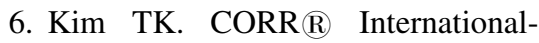
Asia-Pacific: How to live a happy life as an orthopaedic surgeon. Clin Orthop Relat Res. 2017;475:597600.

7. Kim YH, Matsuda S, Kim TK. Clinical faceoff: Do we need special strategies for Asian patients with TKA? Clin Orthop Relat Res. 2016;474:1102-1107.

8. Lasam MP, Lee KJ, Chang CB, Kang YG, Kim TK. Femoral lateral bowing and varus condylar orientation are prevalent and affect axial alignment of TKA in Koreans. Clin Orthop Relat Res. 2013;471:14721483.

9. Ma ZS, Wang L, Du GS, Wang L, Chen XJ. What is the work environment of orthopaedic surgeons in China? Clin Orthop Relat Res. 2014;472:3576-3580.

10. Mullaji AB, Marawar SV, Mittal V. A comparison of coronal plane axial femoral relationships in Asian patients with varus osteoarthritic 
CORR® International-Asia-Pacific

knees and healthy knees. J Arthroplasty. 2009;24:861-867.

11. Nagamine R, Miyanishi K, Miura H, Urabe K, Matsuda S, Iwamoto $\mathrm{Y}$. Medial torsion of the tibia in Japanese patients with osteoarthritis of the knee. Clin Orthop Relat Res. 2003:218-224.

12. Regehr C, Glancy D, Pitts A, LeBlanc VR. Interventions to reduce the consequences of stress in physicians: a review and meta-analysis. J Nerv Ment Dis. 2014;202:353-359.

13. Saleh KJ, Quick JC, Conaway M, Sime WE, Martin W, Hurwitz S, Einhorn TA. The prevalence and severity of burnout among academic orthopaedic departmental leaders. $J$ Bone Joint Surg Am. 2007;89:896903.

14. van Vendeloo SN, Brand PL, Verheyen CC. Burnout and quality of life among orthopaedic trainees in a modern educational programme: Importance of the learning climate. Bone Joint J. 2014;96-B:1133-1138.

15. Won HH, Chang CB, Je MS, Chang MJ, Kim TK. Coronal limb alignment and indications for high tibial osteotomy in patients undergoing revision ACL reconstruction. Clin Orthop Relat Res. 2013;471:35043511. 